\title{
Adapting the Multilingual Assessment Instrument for Narratives (MAIN) to Torwali
}

\section{Zubair Torwali}

Idara Baraye Taleem-o-Taraqi (IBT), Institute for education and development

Torwali, a Dardic language of the Indo-Aryan family spoken in the District Swat in Pakistan, is an endangered language that lacks a literary tradition. This paper gives a background on the Torwali language and people, and describes the development of an orthography for Torwali and the establishment of Torwali-medium schools by the local organization Idara Baraye Taleem-o-Taraqi 'institute for education and development' (IBT). Finally, the process of adapting the Multilingual Assessment Instruments for Narratives (MAIN) to Torwali is outlined.

\section{Introduction}

The Atlas of World Languages in Danger (Moseley, 2010) lists 26 out of the 74 languages spoken in Pakistan as endangered. One of the 26 endangered languages is Torwali, which is rated as 'Definitely Endangered', because it does not have a literary tradition and its speakers are undergoing a rapid language shift toward the predominant language, Pashto, in the areas of Pakistan where children acquire Torwali as their first language (see Section 2).

The Language Impairment Testing in Multilingual Settings - Multilingual Assessment Instrument for Narratives (LITMUS-MAIN, hereafter MAIN; Gagarina et al., 2012; 2015) is a narrative assessment tool developed within the COST Action IS0804 Language Impairment in a Multilingual Society: Linguistic Patterns and the Road to Assessment (2009-2013) and has subsequently been revised in 2019 (Gagarina et al., 2019). This instrument is used to investigate "children's acquisition of narrative skills" (Bohnacker \& Gagarina, 2019, p. iv) from age 3 to 12. It has been designed to allow assessment in several languages in the same child and it also has three different elicitation modes: Telling, Retelling and Model Story. MAIN contains four parallel stories, each with a six pictures sequence. The stories are parallel in their linguistic and cognitive complexity in both micro- and macro structure (Gagarina, et al., 2012). In this paper, the process of adapting MAIN to Torwali is described.

The paper is structured as follow: it first provides an overview of the Torwali language and people (Section 2), and then reports on previous research on Torwali (Section 3), features of Torwali (Section 4), and the development of the standardized Torwali orthography (Section 
5) as well as the Torwali schools that the organization Idara Baraye Taleem-o-Taraqi 'institute for education and development' (IBT), the author's organization, has started (Section 6), after which the process of adapting MAIN to Torwali is described (Section 7). The paper ends with a short conclusion (Section 8).

\section{The Torwali language and people}

Torwali is a Dardic language of the Indo-Aryan family and is mainly spoken in the Bahrain and Chail areas of District Swat in the northwest frontier province, Khyber Pakhtunkhwa, in Pakistan. Figure 1 shows a map of Pakistan indicating the area in which Torwali is spoken as well as a more detailed map of the specific region, District Swat, where it is spoken.

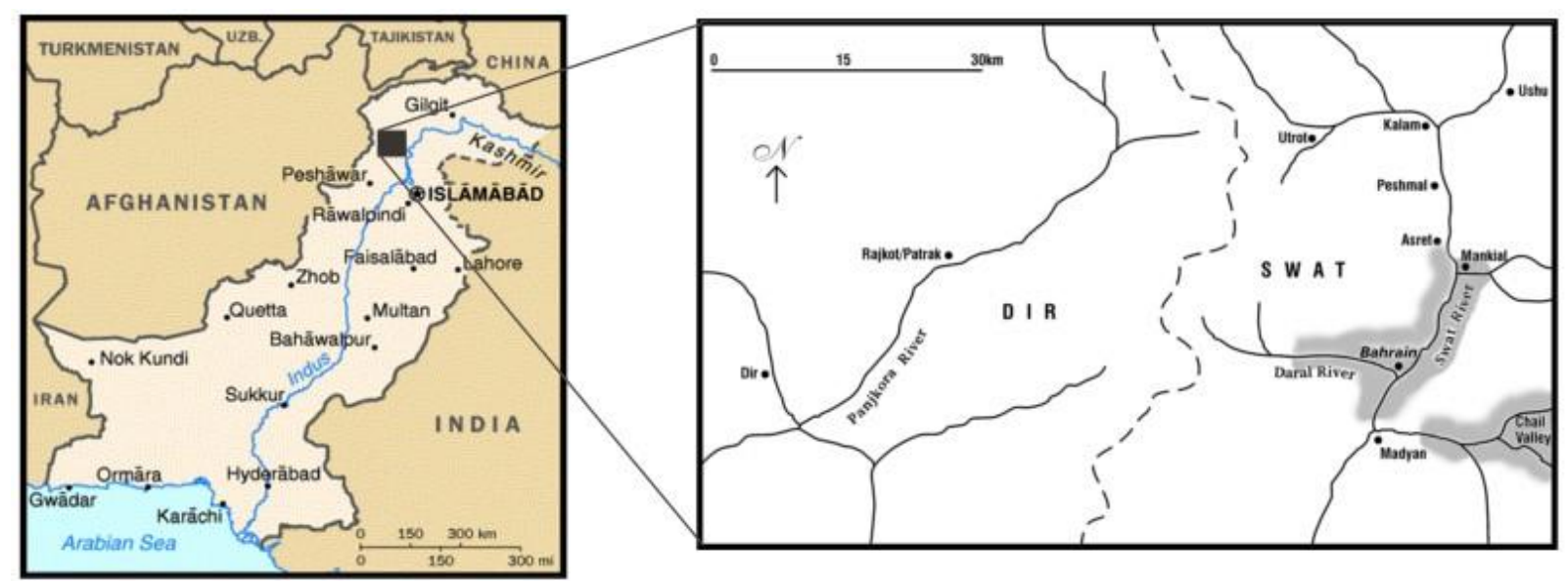

Figure 1. The Torwali-speaking area (District Swat), Pakistan (from Lunsford, submitted, reprinted with permission).

The level of endangerment of the Torwali language can be seen by its small community of speakers, which is estimated to be approximately 80,000 (Lunsford, 2001). However, a recent survey found that a majority $(60 \%)$ of the respondents said that the population of the Torwali community is more than 120,000 (Torwali, 2014). Around 30-35\% of the Torwali speakers have migrated permanently to the larger cities of Pakistan, where they shift to speaking the national language, Urdu, or by other languages of wider communication, such as Pashto or Punjabi.

The Torwali language is said to have originated from the pre-Muslim Dardic communities of Pakistan (Viaro \& Inam-ur-Rahim, 2002). The speakers of Torwali are called Torwalik or Torwal (Grierson, 1929). The area where Torwali is spoken is known as Torwal by other Dardic communities like Gawri and Kohsitani. In Torwali folktales, the entire area is also referred to as Tu:aal (Torwal) (see McCabe, 2019, p. 161). As is common in other Dardic communities in Northern Pakistan, the Torwali people living in the valleys of Bahrain and Madyan in the Swat Valley in Pakistan did not know where they and their language originated. They had largely lost their identity centuries ago because of being invaded by outsiders. The majority of the Torwali attributed, and many still do so, their descent to Arabs by "boasting an 
Arab origin" (Hay, 1934, p. 241) and call themselves Kohistani, an identity given to them by the Pathans (Barth, 1956), who captured their lands and converted them to Islam. The reason for this can be that "the Dards unfortunately did not succeed in arousing comparable interest" (Jetmar, 1961), and that their history and origin remained shrouded in the debris of history. A few reports about them have been written by the British colonial officers during their service in the mountains, but the reports are not generally known (Jetmar, 1961). With the loss of the history, identity and culture of the Torwali people, their language had also become threatened by extinction, mainly because it did not have a written form, and nor could its speakers undertake any measures to promote and develop it.

\section{A short overview of early research on the Torwali language}

In the late $19^{\text {th }}$ and the $20^{\text {th }}$ century, numerous surveys were carried out on Pakistan's endangered languages by individuals and international organizations, including the five volumes of Sociolinguistic Survey of Northern Pakistan (Calvin, Sandra, \& Daniel, 1992) and the Linguistic Survey of India (Grierson, 1928), the latter perhaps being the first book that focuses specifically on the Torwali language. Grierson (1928) is based on field data collected by Sir Aurel Stein, who visited Swat-Kohistan in the Swat Valley in 1926, and includes Torwali texts written using the phonetic alphabet with English translations and a couple of folktales of the Torwali community narrated by a single speaker. Before that, in 1885, John Biddulph dedicated a short chapter of his book, Tribes of Hindoo Koosh, to the Torwali lexicon (Biddulph, 1885). In 1956, Fredrik Barth wrote a chapter on the language, people, economy, political organization, lineage, and habitat of the Torwali community (Barth, 1956).

\section{Some basic features of the Torwali language}

Torwali has two distinct dialects. The dialect with the largest number of speakers is spoken in the main valley to the north beyond the town of Madyan and is usually referred to as the Sinkaen or Bahrain dialect. The other dialect is known as the Chail dialect and is spoken in the Ulaal Dara (Bishigram valley) to the east of the town of Madyan (see Figure 1).

Torwali has 35 consonant phonemes and 13 vowel phonemes (Bashir, 2003; Lunsford, 2001). The syllable structure of Torwali is limited, with only four types of syllables: V, VC, CV, and CVC (Lunsford, 2001). Both Bashir (2003) and Lunsford (2001; submitted) have found four contrastive tone patterns in Torwali: high $(\mathrm{H})$, low $(\mathrm{L})$, rising $\mathrm{LH}$ ) and falling (HL).

The Torwali word order is subject-object-verb (SOV), a pattern that is common in IndoAryan languages. Torwali uses postpositions (Lunsford, 2001), for example [sum mi] 'soil in', [tha:m zed] 'tree on', and [bop si] 'father of'.

In contrast to e.g. English, the Torwali number system is a base-20 system, which means that the numbers 1-20 are all unique forms (although some of the numbers 1-10 are similar to some of the numbers 11-20). Just as the English decimal cycles on every ten, Torwali's system 
cycles on every twenty, e.g., [br:f] 'twenty', [dobr:f] 'forty, lit. two twenty'; [6əbr:f] 'sixty, lit. three twenty', [çวubr:]] 'eighty, lit. four twenty', and so forth.

Grierson (1928) claims that Torwali has eight cases: nominative, accusative, agentive (ergative), instrumental, dative, ablative, genitive, and locative. In contrast, Lunsford (submitted) claims that, grammatically speaking, there are only three grammatical cases: nominative (which is unmarked), ergative and oblique. For example, in a gam ma ap 'I came from the village', the noun gam gam 'village' is unmarked, whereas in a gama ma ap 'I came from the villages', gama 'villages' is marked for the plural oblique case.

There are three tenses in Torwali, past, present, and future, and three aspects, perfective, imperfective, and inceptive. The inceptive aspect is used to mark events about to begin.

\section{Developing an orthography for Torwali and teaching literacy to the community}

Literacy is one of the most complex issues in language revitalization efforts (Grenoble \& Whaley, 2006) and is usually thought of as a first step in the process of revitalizing a language. Since literate individuals and communities are deemed to hold high status in modern societies, making literacy in a language possible can add prestige to it. Literacy in a local language also makes the language suitable to be used in many social domains. For these reasons, many language revitalization efforts focus on putting in place school-based literacy programs. Developing literacy in an endangered language which only has an oral form poses many challenges because in the absence of a writing tradition one comes across the challenge of developing a script or orthography from scratch. The question one faces when thinking about literacy in a local language that is spoken only is how to develop it and where to start. In many cases, minority languages spoken in a community, usually the languages facing challenges of extinction, do not have a writing system, at all. The first step, therefore, has been to develop an orthography for Torwali, which involves a number of social, political, historical, economic, psychological, and linguistic considerations.

The orthography for Torwali was developed by the local organization IBT in 2004-2005. The script is alphabetic, is based on the Perso-Arabic script and is written from right to left. This was the logical choice, since many members of the Torwali people were already familiar with and used this writing system in the national language Urdu, in the "regional" language Pashto (i.e. the language of wider communication in the northwest province of Pakistan, the province of Khyber Pakhtunkhwa), or in Arabic through the Holy Quran. The Torwali alphabeth has 47 letters/written symbols. All of them except four also exist in Urdu. Some dialects of Pashto, for example the Qandahari dialect, use two of these four letters (both consonants). Out of the four unique letters written representations $[\mathrm{s}],[\mathrm{z}],[\mathrm{c}]$ and [æ], respectively, the last one is a vowel, which is used frequently in Torwali. The other three are consonants: the retroflex fricatives [s] and [z], and the palatal fricative [ç] (Torwali, 2015). Figure 2 shows the alphabet, with the four special characters highlighted in red. 


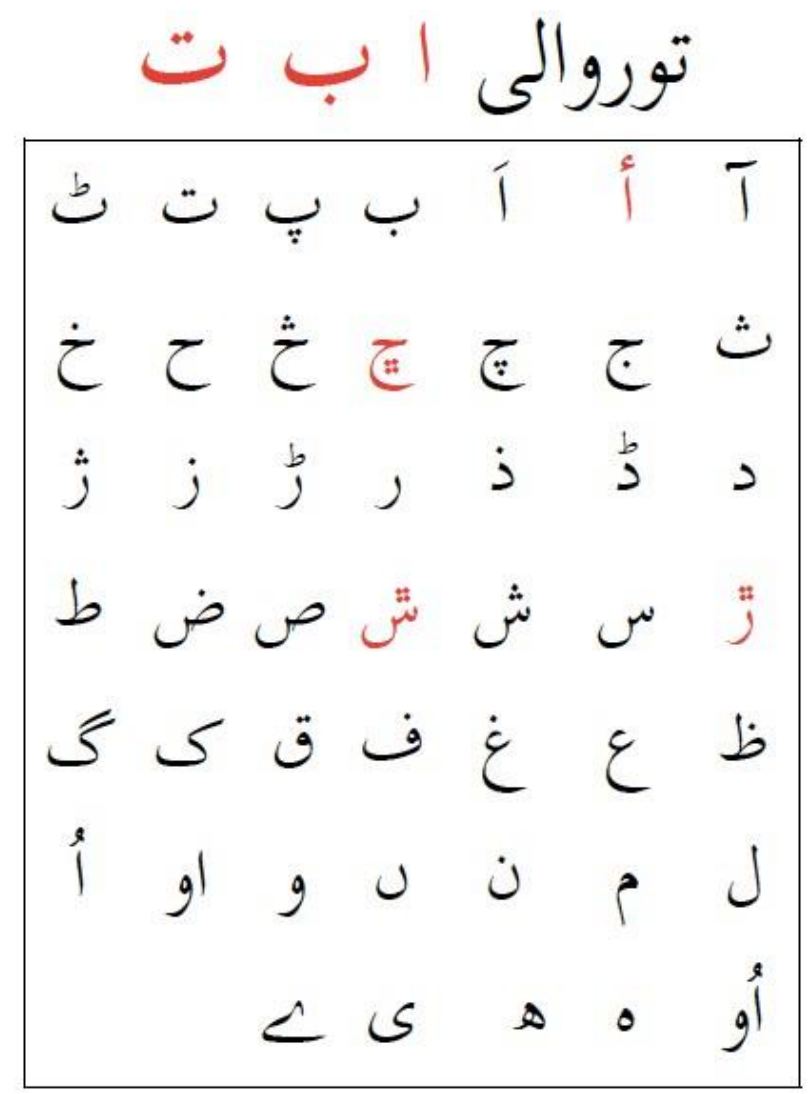

Figure 2. The Torwali alphabet (Torwali, 2007).

The first Torwali alphabet book was developed in 2006 and a primer was published in 2007 (Torwali, 2007). The teaching of Torwali to children was started in 2008 by the local organization, Idara Baraye Taleem-o-Taraqi (IBT). The first school was set up in Bahrain Swat under the name Mhoon School (Torwali, 2012), which means 'our school'. By 2020, four such schools had been started in the Torwali community. In these schools, children start their preprimary education in their mother tongue Torwali, and two more languages, Urdu and English, are added later on. The children who are admitted to these schools are from four to 11 years old. The grades at these schools are kindergarten 1, kindergarten 2, grade 1, grade 2 and grade 3. At the Torwali schools of IBT, the pupils complete two years of their early schooling in Torwali and after that their parents get them admitted to either the public primary schools or to the low-cost private schools. In none of the private or public schools, Torwali is taught, neither as a subject nor as the medium of education. However, most of the teachers use Torwali for giving instructions at these schools as well.

Currently (in 2020), 250 children (both boys and girls) between the ages of 4 and 11 attend the Torwali schools of IBT. (At the time of writing, the schools are closed due to the lockdown instated throughout the country in order to try to contain the Covid19-pandemic). The parents of the pupils are multilingual. The children learn Urdu as a second language at school, and also through the Urdu news and entertainment TV channels which broadcast movies and tv series. A limited number of children are also exposed to Pashto as a second language if this language is spoken by their teachers at schools. 


\section{Adapting MAIN to Torwali}

When starting the process of adapting MAIN to Torwali, MAIN was a new tool for us, but we were familiar with the macrostructure and microstructure of a narrative as we had developed similar stories for our Torwali education program. To be able to adapt MAIN to Torwali, the first thing we had to do was to understand the concepts behind MAIN and its guidelines. In order to fully understand the philosophy of MAIN, we read both the 2012 MAIN manual (Gagarina et al., 2012) and the guidelines for adopting MAIN to new languages (Bohnacker \& Gagarina, 2019) carefully. Our next task was to read, understand and translate the MAIN assessment materials (i.e. guidelines for assessment, protocols, scoring, story scripts, and the background questionnaire).

The four stories, Baby Birds, Baby Goats, Cat and Dog, were found to be appropriate for Torwali-speaking children as they are already familiar with folktales which often have animal protagonists such as dogs, cats, goats, birds, and other animals such as bears, lions, wolves, monkeys, fox, and jackals. The first challenging task was to translate and adapt the four story scripts to Torwali because one has to take great care to keep the various aspects of the micro- and macrostructure comparable to the original (e.g. internal states terms, goals, attempts and outcomes), but at the same time keep the original Torwali information structure and other language-specific aspects. For example, Torwali verbs are usually complex verbs, i.e. a noun plus an action make a verb, e.g. for the English verb 'fly' the Torwali verb would be شيش ديؤ [šiš déo]. The majority of Torwali verbs are constructed in this manner, which makes Torwali sentences longer than their English counterparts. However, otherwise there were no difficulties in translating the story scripts to Torwali. The task of translating the story scripts was given to the IBT team who translated the stories, and then reviewed them multiple times to check the accuracy of the various aspects of the micro- and macrostructure. The number of words, phrases and clauses were considered here along with the goals, attempts, outcomes and the internal state terms. The next challenge has been to translate the scoring sheets, a process that is currently underway. After the scoring sheets have been finalized, we will again review the story scrips because we have experienced that reviewing of a product after a longer time help increase its accuracy.

Next, we plan to carry out a pilot study using MAIN with pupils of the IBT Torwali schools and with pupils of the state-run primary schools. We plan to include 65 pupils from our IBT Torwali schools and 65 from state-run primary schools. It is important for us to keep the number of pupils from the state-run primary schools and from our schools the same because we want to assess and compare the narratives abilities of pupils in both kinds of school systems. The data collection as well as the finalizing of the Torwali MAIN is planned to be completed by summer 2021, as during 2020, the schools have remained closed for longer time because of the Covid19 pandemic. 


\section{$7 \quad$ Conclusion}

Adapting MAIN to Torwali is the first project of its kind in Pakistan. Pakistan is a multilingual country and majority the children and parents speak both a mother tongue and the national language Urdu; in some areas up to four or even five languages may be used. Having access to an assessment instrument such as MAIN will be of great significance for programs such as ours, mother tongue based multilingual education programs. It will help us to improve our pedagogy and teaching materials. It will also help other similar communities who have also been implementing such educational programs. The adaptation of MAIN will also support the educationists in Pakistan who are responsible to develop teaching materials for a multilingual setting. Our organization, the IBT, is very passionate about adapting MAIN and it hopes to begin to use it in late 2020 or early 2021.

\section{$8 \quad$ References}

Barth, F. (1956). Indus and Swat Kohistan-an Ethnographic Survey (Vol. II). Oslo: Forenede Trykkerier.

Biddulph, J. (1885). Tribes of Hinoo Koosh (Vol. 1). Lahore, Pakistan: Ijaz Ahmad, Ali Kamran Publishers.

Bohnacker, U. \& Gagarina, N. (2019). Background on MAIN - Revised, how to use it and adapt it to other languages. ZAS Papers in Linguistics, 63, iv-xii.

Chaghatai, M. I. (2002). Writings of Dr. Leitner: Islam, Education, Dardistan, Politics and Culture of Northern Areas. Lahore, Pakistan: Government College Research and Publication Society \& Sang-e-Meel Publications.

Gagarina, N., Klop, D., Kunnari, S., Tantele, K., Välimaa, T., Balčiūnienė, I., Bohacker, U., \& Walters, J. (2012). MAIN: Multilingual Assessment Instrument for Narratives. ZAS Papers in Linguistics, 56.

Gagarina, N., Klop, D., Kunnari, S., Tantele, K., Välimaa, T., Balčiūnienė, I., Bohnacker, U., \& Walters, J. (2015). Assessment of Narrative Abilities in Bilingual Children. In S. Armon-Lotem, J. de Jong, \& N. Meir (Eds.), Assessing multilingual children: Disentangling bilingualism from language impairment (pp. 243-269). Bristol: Multilingual Matters.

Gagarina, N., Klop, D., Kunnari, S., Tantele, K., Välimaa, T., Bohnacker, U., \& Walters, J. (2019). MAIN Multilingual Assessment Instrument for Narratives - Revised. ZAS Papers in Linguistics, 63.

Grenoble, L. A., \& Whaley, L. J. (2006). Saving Languages: An Introduction to Language Revitalization. Cambridge, UK: Cambridge University Press.

Grierson, G. A. (1929). Torwali: An Account of a Dardic Language in Swat-Kohistan. UK: Asian Educational Services.

Hay, R. W. (1934). The Yousafzai State of Swat. The Geographical Journal, 84(3), 236-246.

Jetmar, K. (1961). Ethnological ReJesearch in Dardistan 1958 preliminary report. Proceedings of the American Philosophical Society, 105(1), 79-97.

Lunsford, W. A. (submitted). A typological profile of Torwali. 
Lunsford, W. A. (2001). An overview of linguistic structures in Torwali. Arlington, Texas, USA: University of Texas.

McCabe, C. (Ed.) (2019). Poems from the Edge of Extinction: An Anthology of Poetry in Endangered Languages. London: Chambers.

Moseley, C. (Ed.) (2010). Atlas of the World's Languages in Danger (3 ed.). Paris: UNESCO Publishing. Online version. Retrieved 24 May 2020, from http://www.unesco.org/culture/en/endangeredlanguages/atlas

Sathanvi, S. S. (2011). Kitab ul Ibra (Vol. 1). Islamabad, Pakistan: Poorab Academy.

Shah, P. M. (1979). Tuwarikh Rahmat Khani. Peshawar: Pashto Academy, University of Peshawar.

Torwali, Z. (2015). Torwali Alif, Bey, Tey [Torwali alphabets] (3 ${ }^{\text {rd }}$ ed.). Bahrain Swat, Pakistan: Idara Baraye Taleem-o-Taraqi (IBT).

Torwali, Z. (2014). Baseline Survey of the status of Torwali language. Bahrain Swat, Pakistan: Idara Baraye Taleem-o-Taraqi (IBT). Available online at: doi:10.13140/RG.2.1.4238.1847

Torwali, Z. (2012). My Education, my language. Retrieved April 4, 2018, from pakistantoday.com.pk: https://www.pakistantoday.com.pk/2012/04/18/my-education-my-language/

Torwali, Z. (2007). Torwali Alif, Bey, Tey [Torwali alphabeths] (1 ${ }^{\text {st }}$ ed.). Bahrain Swat, Pakistan: Idara Baraye Taleem-o-Taraqi (IBT).

Viaro, A., \& Inam-ur-Rahim. (2002). Swat: An Afghan Society in Pakistan. Geneva, Switzerland: City Press and Graduate Institute of Developmental Studies. 